\title{
HISTOMORPHOMETRIC ANALYSIS OF CUTANEOUS REMODELING IN THE EARLY STAGE OF THE SCLERODERMA MODEL
}

\author{
Cristiane Carla de Oliveira, ${ }^{\mathrm{I}}$ Ana Paula Pereira Velosa, ${ }^{\mathrm{I}}$ Edwin Roger Parra, ${ }^{\mathrm{II}}$ \\ Vera Luiza Capelozzi, ${ }^{I I}$ Walcy Rosolia Teodoro, ${ }^{\mathrm{I}}$ Natalino Hajime Yoshinari ${ }^{\mathrm{I}}$
}

doi: 10.1590/S1807-59322009000600014

Oliveira CC, Velosa APP, Parra ER, Capelozzi VL, Teodoro WR, Natalino HY. Histomorphometric analysis of cutaneous remodeling in the early stage of the scleroderma model. Clinics. 2009;64(6):577-83.

INTRODUCTION/OBJECTIVES: Systemic sclerosis, or scleroderma, is a rheumatic disease characterized by autoimmunity, vasculopathy, and fibrosis of the skin and several internal organs. In the present study, our aim was to assess the skin alterations in animals with scleroderma during the first stages of disease induction.

METHODS: To induce scleroderma, female New Zealand rabbits $(\mathrm{n}=12)$ were subcutaneously immunized with $1 \mathrm{mg} / \mathrm{ml}$ of collagen V (Col V) in complete Freund's adjuvant, twice with a thirty-day interval. Fifteen days later, the animals received an intramuscular booster with type V collagen in incomplete Freund's adjuvant, twice with a fifteen-day interval. The control group was inoculated with $1 \mathrm{ml}$ of $10 \mathrm{mM}$ acetic acid solution diluted with an equal amount of Freund's adjuvant. Serial dorsal skin biopsies were performed at 7, 15, and 30 days and stained with H\&E, Masson's trichrome and Picrosírius for morphological and morphometric analyses.

RESULTS: Immunized rabbits presented a significant increase in collagen in skin collected seven days after the first immunization $(\mathrm{p}=0.05)$.

CONCLUSION: The results from this experimental model may be very important to a better understanding of the pathogenic mechanisms involved in the beginning of human SSc. Therapeutic protocols to avoid early remodeling of the skin may lead to promising treatments for SSc in the future.

KEYWORDS: Skin remodeling; Systemic sclerosis; Type V collagen; Autoimmunity; Rabbits.

\section{INTRODUCTION}

Systemic sclerosis (SSc), or scleroderma, is a disease of unknown etiology characterized by vascular involvement, autoimmunity, and fibrosis of the skin and internal organs. ${ }^{1-2}$ Thickening of the skin is the hallmark of the disease, ${ }^{3}$ and the extent of cutaneous involvement has been shown to influence patient abilities, ${ }^{4}$ activities, ${ }^{5}$ and outcomes. ${ }^{6}$

The most prominent pathologic manifestation of the disease is an accumulation of extracellular matrix

\footnotetext{
${ }^{\text {I }}$ Discipline of Rheumatology, Faculdade de Medicina da Universidade de São Paulo - São Paulo/SP, Brazil.

II Department of Pathology, Faculdade de Medicina da Universidade de São Paulo - São Paulo/SP, Brazil.

Email: matrix@lim17.fm.usp.br

Tel: 55113061.7211

Received for publication on December 18, 2008

Accepted for publication on March 09, 2009
}

components, predominantly collagen types I and III, ${ }^{7-12}$ but also types $\mathrm{VI}^{13}$ and VII. ${ }^{14}$

The current authors have previously described changes in anatomical distribution of collagen and its consequences, ${ }^{15}$ they have also described an experimental model of SSc in rabbits after immunization with type $\mathrm{V}$ collagen $(\mathrm{COL} \mathrm{V})^{16}$, but not with other types of collagen. These animals developed progressive fibrosis and vascular involvement in all organs usually affected by SSc. ${ }^{16-20}$ Antinuclear, anti-Scl70 ${ }^{21}$, and anti-collagen type I, III, and V antibodies were found in the serum of these animals, as were immunocomplexes..$^{20}$ The same authors suggested that the fibrosis development in these animals at 75 and 120 days following initial immunization with $\mathrm{Col} \mathrm{V}$ was a consequence of an antigen versus antibody reaction occurring at the endothelial cell surface. They hypothesized that immunocomplexes deposited at the endothelial cell layer could activate these cells to release pro- 
inflammatory mediators such as TGF beta and endothelin, stimulating fibroblasts to synthesize collagen. However, it was uncertain whether other mechanisms could be involved in the remodeling process and when these mechanisms started in the experimental model. The aim of the present study was to evaluate the amount of collagen in the skin of rabbits at 7, 15, and 30 days after immunization with $\mathrm{Col} \mathrm{V}$ with the purpose of verifying the changes during the early stage of immunization to induce experimental SSc. It was hypothesized that the augmentation of collagenous fibers occurs early in the skin of rabbits after immunization with collagen $\mathrm{V}$.

\section{MATERIALS AND METHODS}

\section{Complete Immunization Protocol}

To induce experimental SSc in healthy New Zealand female rabbits, the complete immunization protocol (Figure 1) included four inoculations. The first was a subcutaneous (sc) injection of $1 \mathrm{mg}$ of $\mathrm{Col} \mathrm{V}$ isolated from human placenta, diluted in $1 \mathrm{ml}$ of $10 \mathrm{mM}$ acetic acid and added to an equal amount of complete Freund's adjuvant (Sigma Chemical Co.; St. Louis, Missouri, USA). The second inoculation occurred 30 days later via an identical subcutaneous injection. Fifteen days after the second subcutaneous injection, the rabbits received one reinforcement dose of $1 \mathrm{mg}$ of Col V plus 1 $\mathrm{ml}$ of incomplete Freund's adjuvant intramuscularly (third inoculation). Finally, a second identical reinforcement (fourth inoculation) was administrated after another 15 days. ${ }^{16-18}$

\section{Early Stage of the Immunization Protocol}

To study the early stage of immunization (Figure 1), seventy-day-old healthy New Zealand female rabbits $(\mathrm{N}=12)$ received $1 \mathrm{mg} / \mathrm{ml}$ of Col V plus complete Freund's adjuvant subcutaneously (sc). After being anesthetized, each animal was subjected to a series of sequential skin biopsies carried out in distinct dorsal regions at $7(\mathrm{~N}=4$, group 7 days $), 15$
( $\mathrm{N}=4$, group 15 days), and $30(\mathrm{~N}=4$, group 30 days) days after immunization; the animals were sedated with an aqueous solution of $2 \%$ cloridrate of 2-(2, 6-xylidine)-5, 6-dihydro-4H-1,3-tiazine (Rompum, Bayer do Brasil S. A), and anesthetized after five minutes with $1 \mathrm{M}$ ketamine cloridrate (Ketalar, Park-Davis). The samples collected were immersed in $10 \%$ formaldehyde for $24 \mathrm{hrs}$, embedded in paraffin, cut into 3-4 $\mu$ m-thick slices, and stained with hematoxylin and eosin (H\&E), Masson's trichrome, and Picrosirius.

Control groups were represented by rabbits inoculated with $1 \mathrm{ml}$ of $10 \mathrm{mM}$ acetic acid solution diluted with an equal amount of complete Freund's adjuvant, with the skin sample collection carried out during the same periods used for the study groups $(7,15$, and 30 days).

\section{Histomorphometric analysis}

To characterize the collagenous fibers in the dermis, Masson's trichrome was used to stain some of the collagencontaining fibers in blue.

Collagen fiber density was evaluated in the dermis of each biopsy specimen after the first COL V inoculation by the Picrosirius polarization method. ${ }^{22}$ This method permits determination of the location of collagen-containing fibers in the skin by intensifying the normal birefringence of collagenous fibers. The content of collagen fibers in the dermis was determined by an image analysis system in which a charge-coupled device Sony DXC-101 camera is coupled to a Zeiss Axioplan microscope, from which the images are then sent to a monitor (Trinitron Sony). By means of a digitizing system (Oculus TCX, Coreco; St Laurent, Quebec, Canada) inserted into a computer (Pentium, 133 $\mathrm{MHz}$ ), the images were processed by software (BioscanOptimas 5.1; Bioscan, Edmonds, Washington, DC, USA). The enhancement of collagen birefringence promoted by the Picrosirius polarization method is specific to collagenous structures composed of aggregates of orientated molecules. The threshold for collagenous fibers was established for each

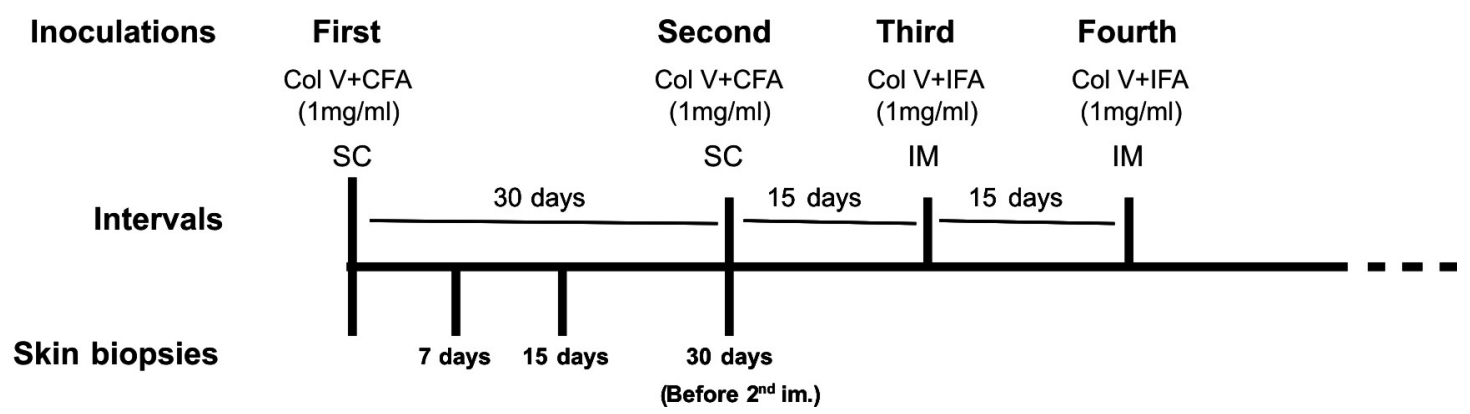

Figure 1 - Illustration of the immunization protocol and temporal skin biopsies. Col V=Collagen V; CFA=Complete Freund's adjuvant; IFA=Incomplete Freund's adjuvant; $\mathrm{SC}=$ Subcutaneous; IM=Intramuscular. 
slide after enhancing the contrast up to a point at which the fibers were easily identified as birefringent (collagen) bands. The area occupied by the fibers was determined by digital densitometric recognition via adjustment of the threshold level of the measurement to include all fibers of the collagenous system. Collagen content was measured in the distinct layers of the dermis, and is expressed as the relationship between the quantity of collagen fibers divided by the total area of dermis studied. The area of dermis in each specimen was carefully measured in the image analysis system using a cursor that permits free determination of the area below the epidermis and basement membrane. The results display the amount of fibers in the collagenous systems (in area) per total area of dermis, and are expressed as a fraction.
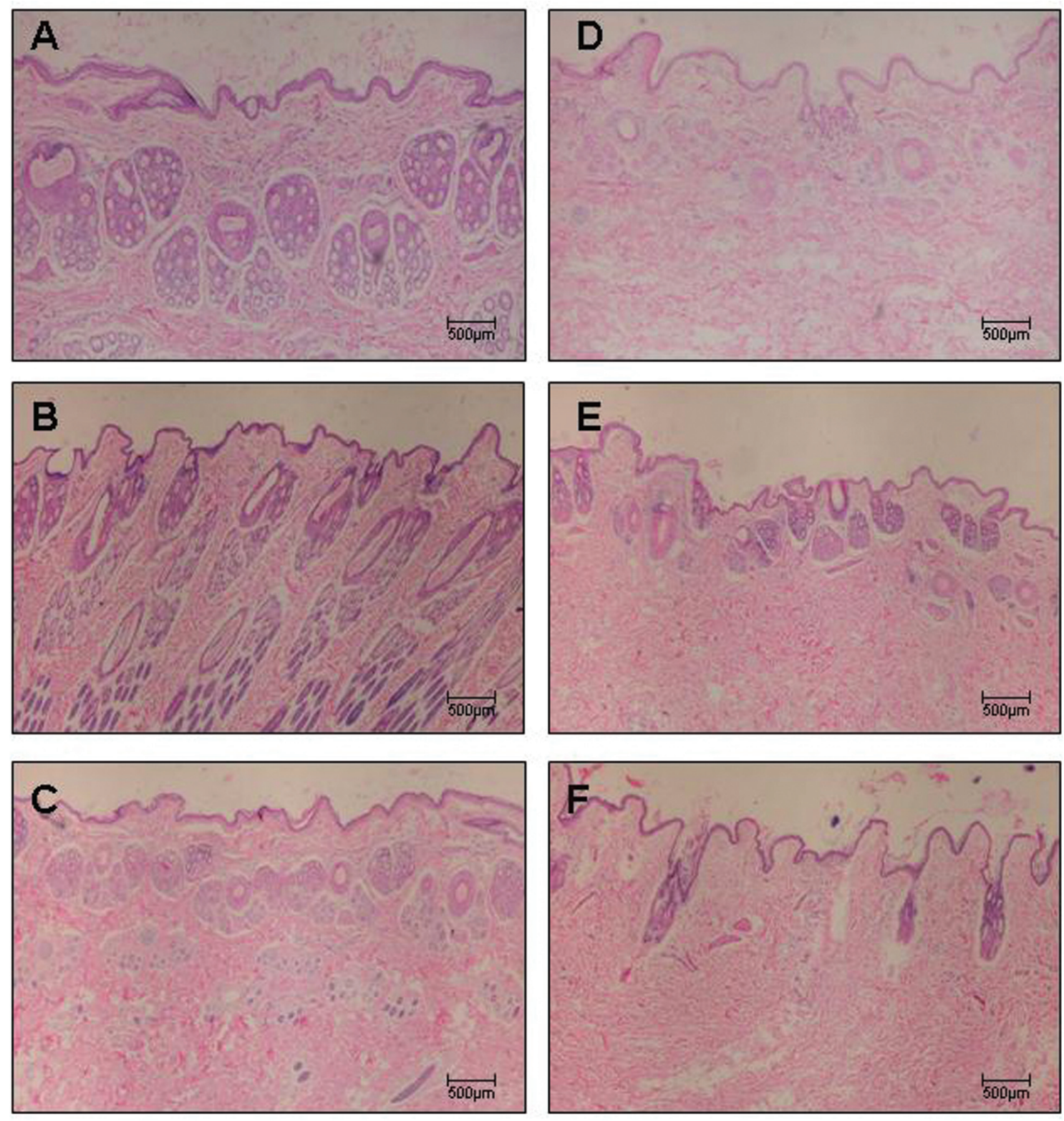

Figure 2 - Panels (A - C) depict control rabbit skin samples stained with H\&E collected after 7, 15, and 30 days, respectively. Panels (D - F) depict skin samples of immunized rabbits stained with $\mathrm{H} \& \mathrm{E}$ collected after 7, 15, and 30 days, respectively. Magnification: 40X.

\section{Statistical analysis}

The quantitative results are expressed as means $\pm \mathrm{SD}$. The t-test was used to verify differences between the means of the study and control groups. SPSS version 14.0 software was used for all statistical analyses, and the significance level was set at $5 \%{ }^{23}$

\section{RESULTS}

\section{Histological analysis}

Figures 2A-2F, 3A-3F, and 4A-4F show skin samples obtained from normal and immunized rabbits that were
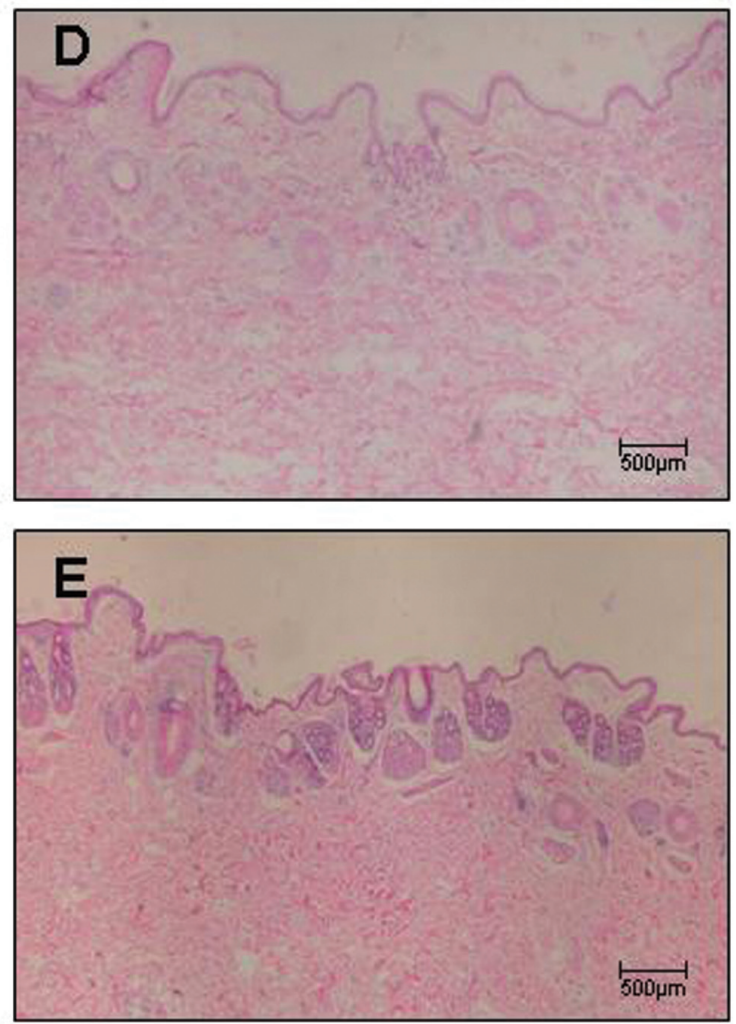
stained with H\&E, Masson's trichrome, and Picrosírius under polarized light, respectively. Preservation of the architecture in the dermis can be observed in control animals (Figure 2A-C and Figure 3A-C), coincident with the weak yellow birefringence of the fibers (Figure 4A-C). In contrast, the skin of rabbits examined seven days after the first inoculation (Figure 2D-F, Figure 3D-F) presented distortion of the architecture and increased reddish-yellow birefringence in the dermis, indicating the presence of thick fibers characteristic of the fibrotic process (Figure 4D-F).

\section{Histomorphometric Analysis}

Table 1 shows the distribution of the means and standard deviation values according to measurements of collagen at days 7,15 , and 30 .

A significant increase in collagen fibers was found in the dermis of animals belonging to the immunized group at seven days compared to controls $(9.72 \pm 3.41$ vs. $6.54 \pm 0.94$; $\mathrm{p}=0.05$ ) (Figure 5). Additionally, the collagen fiber density in the dermis of animals belonging to the 15 and 30-day
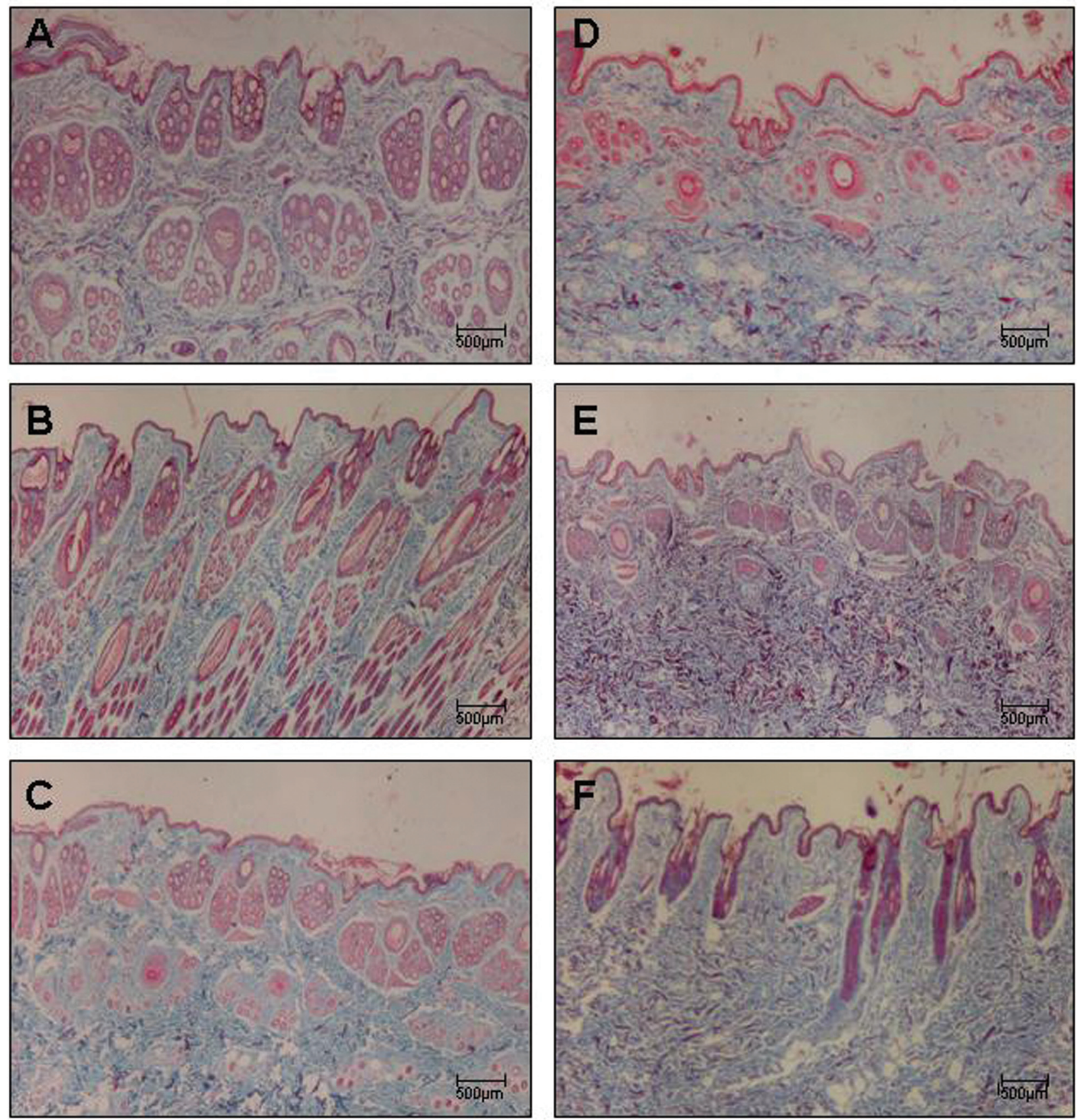

Figure 3 - Panels (A - C) depict control rabbit skin samples stained with Masson's trichrome collected after 7, 15, and 30 days, respectively. Panels (D - F) depict skin samples of immunized rabbits stained with Masson's trichrome collected after 7, 15, and 30 days, respectively. Magnification: 40X. 

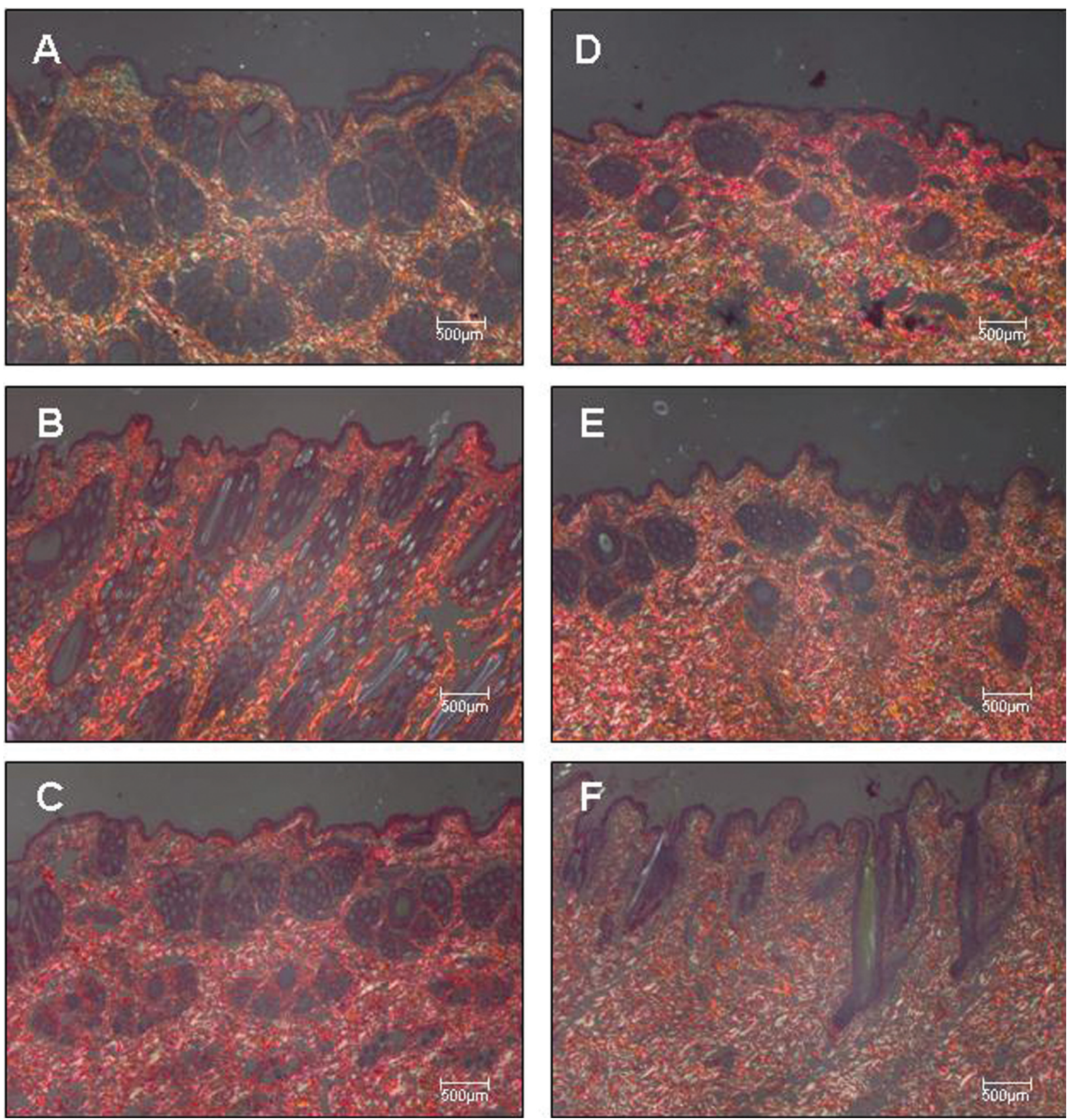

Figure 4 - Panels (A - C) depict control rabbit skin samples stained by Picrosirius and observed under polarized light collected after 7, 15, and 30 days, respectively. Panels (D - F) depict skin samples of immunized rabbits stained by the Picrosirius method and observed under polarized light collected after 7, 15, and 30 days, respectively. Magnification: 40X.

groups was also increased when compared to the control group, although the differences did not reach statistical significance.

\section{DISCUSSION}

In the present study, we demonstrated that the increase in collagen is observed from seven days after the first immunization. The increased collagen density persists 15 and 30 days after the first immunization.
This finding refutes the idea that collagen deposition is due to antibody production because, in the standard immunization process, the antibodies are usually present 15-30 days after the first immunization. In fact, we have previously found that in this early stage, the anti-collagen I, III, and V antibodies are not present (unpublished data). These findings are also supported by previous work using the same experimental model that demonstrated the presence of auto-immunity by detecting anti-nuclear (ANA) and anti-collagen I, III, 
Table 1 - Measurements analysis of collagen fibers in the dermis of animals in the immunized and control groups at 7,15 , and 30 days.

\begin{tabular}{lccc}
\hline Collagen fibers & Mean & Standard Deviation & $\mathrm{P}^{*}$ \\
\hline Group 7 days & 9.72 & 3.41 & $0,05^{*}$ \\
Control group 7 days & 6.54 & 0.94 & \\
\hline Group 15 days & 10.24 & 2.77 & 0,17 \\
Control group 15 days & 8.35 & 1.49 & \\
\hline Group 30 days & 9.59 & 2.75 & 0,24 \\
Control group 30 days & 8.07 & 1.17 & \\
\hline
\end{tabular}

Results analyzed by the t-test to verify differences between the means of the measurements of collagen fibers in immunized and control groups at 7, 15, and 30 days at a significance level of 0.05 . *Statistically significant.

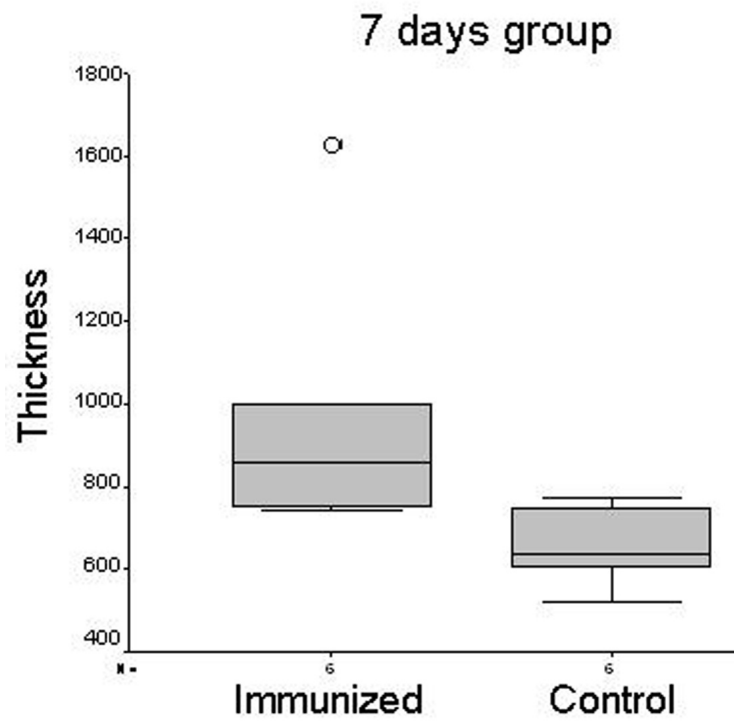

Figure 5 - Box plots illustrating the significant difference $(\mathrm{p}=0.05)$ in the degree of collagen thickening between control and immunized animal samples collected after seven days.

IV, and V antibodies 75 and 120 days after the first sensitization. ${ }^{20,21}$

The increased collagen content detected during early stages of immunization ceased at the end of animal immunization. However, morphological analysis 75 and 120 days after the first sensitization demonstrated that skin remodeling by collagen deposit was progressive. ${ }^{17}$ Furthermore, immunological abnormalities emerged during the late stage of animal disease and, to reinforce the continuity of the inflammatory process, we proved that circulating immunocomplexes do not diminish when Col V immunization ceases. ${ }^{20}$ At this point, one question emerged: how can the perpetuation of histological damage and continuous collagen synthesis be explained? The answer derives from the particularities of Col V. It is a hidden molecule, found composing heterotypic fibrils together with collagen types I and III. Beyond this aspect, Col V is highly immunogenic, since it preserves globular and telopeptide domains. The delayed animal immunization with this protein probably promotes endothelial-basement rupture and further exposition of $\mathrm{Col} \mathrm{V}$ epitopes normally found hidden inside heterotypic fibrils. This process generates fragments of $\mathrm{Col}$ $\mathrm{V}$ (neoantigens). Most likely, these neoantigens will activate the immunological system to produce higher amounts of anti-collagen $\mathrm{V}$ antibodies, increasing the presence of circulating immunocomplexes, which in turn perpetuate continuous vascular aggression and collagen synthesis.

Finally, the results obtained using this experimental model may be very important to a better understanding of the pathogenic mechanisms involved in the beginning of human SSc. Therapeutic protocols to avoid early remodeling of the skin may lead to promising treatments for SSc in the future.

\section{ACKNOWLEDGEMENTS}

This study was supported by the following Brazilian agencies: Foundation for the Support of Research of the State of São Paulo (FAPESP: 2004/15701-5) and Laboratories for Medical Research (LIMs), University Hospital, School of Medicine, University of São Paulo, as well as Federico Foundation Grants. We thank Cassia Arruda for preparing the skin slides.

\section{REFERENCES}

1. Black CM, Stephens C. Systemic sclerosis (scleroderma) and related disorders. In: Maddison PJ, Isenberg DA, Woo P, Glass DN. Textbook of Rheumatology. ed. Oxford: Oxford University Press; 1993. pp. 77189.

2. Derk CT, Jimenez SA. Systemic sclerosis: current views of its pathogenesis. Autoimmunity Rev. 2003;2:181-91.

3. Varga J, Abraham D. Systemic sclerosis: a prototypic multisystem fibrotic disorder. J Clin Investigation. 2007;11:557-67.
4. Poole JL, Steen VD. The use of the health assessment questionnaire (HAQ) to determine physical disability in systemic sclerosis. Arthritis Care Res. 1991;4:27-31.

5. Clements PJ, Wong WK, Hurwitz EL, Furst DE, Mayes M, White B, et al. Correlates of disability index of health assessment questionaire: a measure of functional impairment in systemic sclerosis. Arthritis Rheum. 1999;42:2372-80. 
6. Clements PJ, Hurwitz EL, Wong WK, Seibold JR, Mayes M,White B, et al. Skin thickness as a predictor and correlate of outcome in systemic sclerosis. High Dose versus low dose penicillamine trial. Arthritis Rheum. 2000;43:2445-54.

7. Le Roy EC. Increased collagen synthesis by scleroderma fibroblasts in vitro. A possible defect in the regulation or activation of the scleroderma fibroblasts. J Clin Invest. 1974;54:880-9.

8. Buckingham RB, Prince RK, Rodnan GP, Taylor F. Increased collagen acumulation in dermal fibroblasts cultures from patients with progressive systemic sclerosis (scleroderma). J Lab Clin Med. 1978;92:5-21.

9. Fleismajer R, Perlish JR, Krieg T, Timpl R. Variability in collagen and fibronectin sysnthesis by scleroderma fibroblasts in primary culture. $\mathrm{J}$ Invest Dermatol. 1981; 76:400-3.

10. Fleishmajer R, Dessau W, Timpl R, Krieg T, Luderschmidt C, Wiestner M. Immunofluorescence analysis of collagen, fibronectin and basement membrane protein in scleroderma skin. J Invest Dermatol. 1980;75:2704.

11. Perlish JF,Lemlich G, Fleischmajer R. Identification of Collagem fibrils in scleroderma skin. J Invest Dermatol. 1988;90:48-54.

12. Søndergaard K, Heickendorff L, Risteli L, Risteli J, Zachariae H, Stengaard-Pedersen K, et al. Increased levels of type I and III collagen and hyaluronan in scleroderma skin. Br J Dermatol. 1997;136:47-53.

13. Takasaki S, Fujiwara S, Shinkai H, Ooshima A. Human type VI collagen: purification from human subcutaneous fat tissue and an immunohistochemical study of morphea and systemic sclerosis. J Dermatol. 1995;22:480-5.

14. Rudnicka L, Varga J, Christiano AM, Iozzo RV, Jimenez AS, Uitto J. Elevated expression of type VII collagen in the skin of patients with systemic sclerosis. J Clin Invest. 1994; 93:1709-15.
15. Satomi E, Teodoro WR, Parra ER, Fernandes TD, Velosa AP, Capelozzi VL, et al. Changes in histoanatomical distribution of types I, III and $\mathrm{V}$ collagen promote adaptative remodeling in posterior tibial tendon rupture. Clinics. 2008; 63:9-14.

16. Teodoro WR, Velosa AP, Witzel SS, Garippo AL, Farhat C, Parra ER, et al. Architectural remodeling in lungs induced by type $\mathrm{V}$ collagen immunization: a preliminary morphologic model to study difuse conective tissue disease. Pathol Res Pract. 2004;200:681-91.

17. Bezerra MC, Teodoro WR, Oliveira CC, Velosa APP, Ogido LTI, Gauditano G, et al. Scleroderma-like remodelling induced by type V collagen. Arch Dermatol Res. 2006; 298:51-7.

18. Teodoro WR, Miron BG, Ogido LT, Velosa APP, Abatepaulo F, Capelozzi $\mathrm{VL}$, et al. Synovial remodelling process induced by type $\mathrm{V}$ collagen immunization in rabbits. Pathol Res Pract. 2003;199:605-12.

19. Yoshinari NH, Teodoro WR, Ogido LTI, Velosa APP, Prizon CP, Miron $\mathrm{B}$, et al. Modelo experimental de doenças difusas do tecido conjuntivo (DDTC) induzido por colágeno do tipo V. Rev Bras Reumatol. 2002:42:295-305.

20. Yoshinari NH, Callado MR, Velosa APP, Viana VTS, GoldeinsteinSchainberg C, Carrasco S, et al. Experimental Model of Scleroderma Induced in Rabbits. Arthritis Rheum. 2005; 52(9):s369.

21. Callado MR, Viana VS, Vendramini MB, Leon EP, Bueno C, Velosa AP, et al. Autoantibody profilie in the experimental model of scleroderma induced by type V human collagen. Immunology. 2007;122:38-46.

22. Montes GS. Structural biology of the fibers of the collagenous and elastic systems. Cell Biol Intermed. 1996;20:15-27.

23. SPSS Statistical software Version 10.0. SPSS Inc, Chicago; 2002. 
